\title{
Confidential reporting system for physicians' health proposed
}

Published at www.cmaj.ca on Aug. 26

I $\mathrm{n}$ a bid to protect physician privacy, the Canadian Medical Protective Association (CMPA) is calling for the creation of a nonjudgemental, voluntary and confidential reporting system for the personal health information of its 78500 member physicians.

Some regulatory colleges and an increasing number of hospitals have, under the auspices of protecting the public, recently introduced requirements for physicians to disclose their personal health information when they apply for or renew their licences or hospital privileges.

But mandatory disclosure and punitive approaches to identifying physicians' personal health issues may push doctors to hide medical problems and delay necessary treatment if they feel the repercussions of reporting will affect their ability to practise, according to the association, which provides medico-legal protection to Canadian physicians.

"The unintended consequence of [mandatory reporting of personal health issues] is to increase the stigma associated with ill health and to threaten patient safety rather than improve it. We must remember that a physician's present or past history of illness does not equate to impairment," said Dr. Anne Doig, former president of the Canadian Medical Association (CMA) and member of the CMPA, who spoke at an education session on the subject in Niagara Falls, Ontario on Wednesday.

According to the CMPA, questions asked on licence renewal forms and applications do not appear to be limited to conditions or health issues that may affect patient safety. Those include ones that ask applicants to disclose if they have ever had any alcohol or drug problems, regardless of whether or

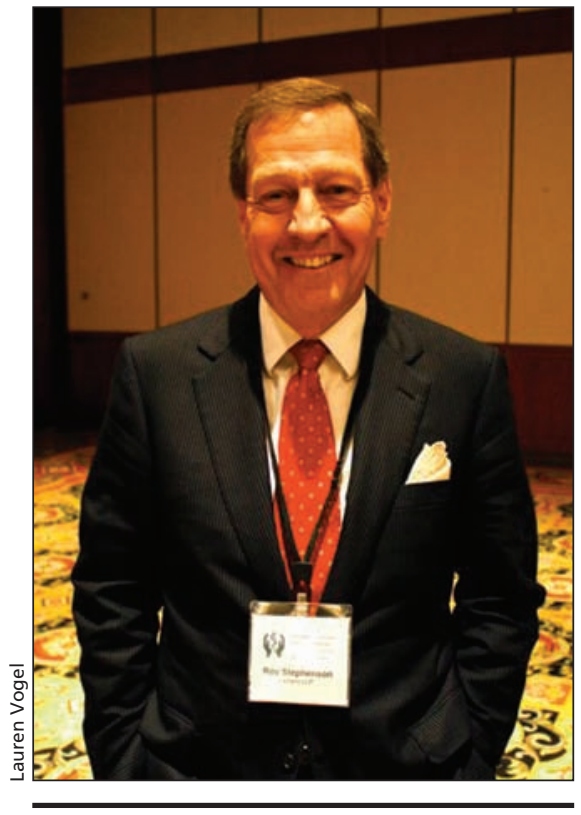

"I don't know of a hospital that doesn't leak like a sieve when it comes to personal health information," said Roy Stephenson, a partner at Lerners LLP in Toronto, Ontario.

when those problems may have been diagnosed or treated.

The association recommended questions of this nature should only be directed to physicians who have been diagnosed with a drug or alcohol problem and who have indicated they are not yet responding to treatment or have voluntarily ceased treatment.

The association also recommended authorities should only collect information essential for the protection of patient safety and relevant to the specific area of medicine. For example, questions concerning blood-borne pathogens should be limited to those practitioners who are deemed to be at an increased risk of transmission.

At the heart of the issue is a concern that the benefits of screening all doctors for health issues that may affect patient safety are outweighed by the negative effects "outing" doctors can have on their reputation and ability to practise.
"The actual risk to patient safety, even in the case of blood-borne pathogens, ranges from infinitesimally small to negligibly small," said Dr. John Gray, CEO and executive director of the CMPA. "Our perception is based on old information before the days of universal precautions and new therapies that mitigate the impact on patient care."

According to Gray, improvements in antiviral therapy have resulted in the majority of patients infected with hepatitis B and HIV undergoing therapy having plasma viral loads below the level of detection. Meanwhile, hepatitis $\mathrm{C}$ infection can be cured in approximately $55 \%$ of patients.

Advances made in procedural responses to medical conditions further mitigate the risk, he said. The implementation of universal precautions has substantially reduced the risk of transmission from blood-borne pathogens to and from health care providers by reducing exposures to patient body fluids.

Nevertheless, physicians who disclose such personal health issues often become the subject of gossip and disciplinary restrictions.

"I don't know of a hospital that doesn't leak like a sieve when it comes to personal health information," said Roy Stephenson, a partner at Lerners LLP in Toronto, Ontario.

While regulatory colleges are experienced in dealing with sensitive information concerning their physician members and generally have transparent and publicly accountable processes through which to render decisions regarding a physician's professional conduct and competence, the same infrastructure, processes, and procedures are much less evident at the hospital level.

This is particularly true for smaller institutions that may, due to resource constraints, be unable to implement the 
necessary information firewalls and blind procedures to make wellinformed decisions regarding physicians' medical conditions and the impact on their practice.

"Physicians have checked into hospitals under an assumed name or gone to different cities. When I've been a patient, within a few hours I've been visited by colleagues who had no reason to know I was in hospital. We're big gossips and we have to change that," said Dr. Trevor Theman, registrar of the College of Physicians and Surgeons of Alberta.
Physicians have few supports in place, should they be required to step down from their practice, said Gray. "I find it intriguing that society responds with compassion to firefighters and policemen who get injured on the job, but that compassion doesn't extend to physicians."

CMPA suggested hospitals hand over questions of physician competence to regulatory colleges to handle, and urged physicians not to report risks that are a mere possibility, where legally possible.

While the CMPA wrestled with questions of the privacy of physicians' health information, CMA also recognized the inadequacy of current procedures for handling medical records during the final day of its annual general meeting.

Delegates moved that the CMA develop a national strategy for longterm retention, retrieval and disposal of medical records. Among other measures adopted was a controversial call for a national ban on mixed martial arts prize fighting. - Lauren Vogel, CMAJ

DOI:10.1503/cmaj.109-3357 